\title{
Diffuse Interstitial Pulmonary Fibrosis with Recovery
}

\author{
R. E. MIDWINTER, J. APLEY, and D. BURMAN \\ From Bristol Royal Hospital for Sick Children
}

Since 1944, when Hamman and Rich published their third paper on diffuse interstitial pulmonary fibrosis, details of many cases have been recorded: the subject has recently been reviewed by Livingstone, Lewis, Reid, and Jefferson (1964). There are, however, comparatively few reports of the occurrence of the syndrome in childhood. Cases in children, with histological verification, have been reported by Bradley (1956), Grant, Hillis, and Davidson (1956), Donohue (1956), Aranson (1956), Baar and Braid (1957), Feinerman and Harris (1957), Mann (1959), Donohue, Laski, Uchida, and Munn (1959), Vestermark (1961), Hilton and RendleShort (1961), and Ivemark and Wallgren (1962). The ages of the children ranged from 3 months to 13 years, and death was reported in all but 3 . There are no reports from English-speaking countries of recovery of a child with the histologically-proven syndrome: the following case is, therefore, of interest.

\section{Case Report}

A 13-year-old boy was first seen at Bristol Children's Hospital in October 1962, with an 8-month history of increasing breathlessness and cyanosis on exercise. He had previously been well and there was no relevant family history. At this time, he was unable to walk more than 100 yards on the flat without stopping, and he had to rest while climbing one flight of stairs. For 2 months he had had a non-productive, shallow cough. On examination, he was noted to be plethoric at rest and cyanosed on exertion. The temperature was normal and there was no finger clubbing. There was dyspnoea at rest, with a respiratory rate of 35 per minute, but nothing abnormal was found clinically in the lungs. The cardiovascular system was normal apart from accentuation of the pulmonary second sound. There were no other abnormal clinical findings.

Investigations. Haemoglobin $15 \mathrm{~g} . / 100 \mathrm{ml}$; white blood cell count and film normal; ESR $3 \mathrm{~mm}$./1 hour; Heaf test negative; Mantoux test $(1: 3,000$ and $1: 100)$ negative; sputum, gastric washings, and urine showed no tubercle bacilli; sputum contained no fungi or haemosiderin; lumbar puncture CSF normal; tests for LE cells

Received September 13, 1965. and for psittacosis and Q-fever antibodies negative; ECG normal; Kveim test negative; liver biopsy normal; serum alkaline phosphatase $37,35,31 \mathrm{KA}$ units, returning to normal in 3 months; serum bilirubin normal.

Chest radiograph showed diffuse mottling throughout both lung fields (Fig. 1a).

Respiratory function tests: resting ventilation 11 litres/min.; respiratory rate 39/min.; vital capacity 950 $\mathrm{ml}$. (predicted normal 2,500 ml.); spirogram showed no evidence of expiratory obstruction; arterial blood $\mathrm{pH}$ $7 \cdot 45, \mathrm{CO}_{2}$ tension $31 \mathrm{~mm}$. $\mathrm{Hg}$ at rest and on exercise; oxygen saturation $96 \%$ at rest and $89 \%$ on exercise.

Lung biopsy. Because of the indirect evidence from these findings, a lung biopsy was performed. Histology demonstrated fibrous interstitial thickening of the alveolar walls throughout the specimen with the exception of those alveoli immediately beneath the pleura. The bronchioles and a few alveoli contained some foamy macrophages and there were occasional lymphocytes in the interstitial tissues. There was no evidence of active inflammation (Fig. 2a and 2b).

Diagnosis. The reduced vital capacity, normal expiratory curve, overventilation with low arterial $\mathrm{CO}_{2}$ tension, and the fall in oxygen saturation with exercise were compatible with a diffusion defect associated with pulmonary infiltration limiting lung expansion. Lung biopsy showed that this was due to a diffuse interstitial pulmonary fibrosis.

Response with treatment. In view of the fairly rapid progression of symptoms and the poor prognosis, the patient was given prednisolone $10 \mathrm{mg}$. b.d. initially, reducing to $5 \mathrm{mg}$. b.d. after 3 months and $5 \mathrm{mg}$. daily after 6 months. He was discharged home after a 2month stay in hospital and was seen at intervals as an outpatient. Two months after steroids were started there was symptomatic improvement: the patient said that he felt less breathless when walking on the flat. Four months later there was no further cyanosis on exercise and the patient became breathless only on walking uphill. Further chest radiographs showed progressive improvement. After 12 months, prednisolone was stopped; there was then no diminution of exercise tolerance and the chest radiograph was within normal limits (Fig. 1b). Since that time the patient has remained well.

Respiratory function was reassessed 2 years after the 


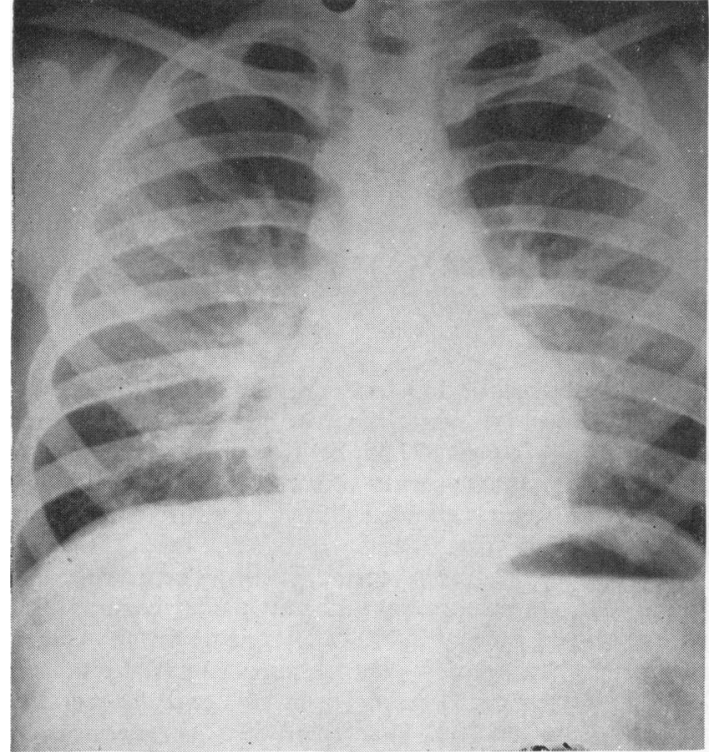

FIG. 1a.-Chest radiograph before treatment, showing diffuse mottling throughout both lung fields.

original investigation and a year after treatment had been stopped. The results were as follows.

Vital capacity $2,975 \mathrm{ml}$; ; residual volume $760 \mathrm{ml}$.; total lung capacity $3,585 \mathrm{ml}$; minute volume at rest 6 litres; respiratory rate $19 / \mathrm{min}$; helium distribution time 4 minutes; steady state CO diffusing capacity at rest $9.5 \mathrm{ml} . / \mathrm{min} . / \mathrm{mm}$. $\mathrm{Hg}$ and on exercise $13.5 \mathrm{ml} . / \mathrm{min} . /$ $\mathrm{mm}$. $\mathrm{Hg}$; maximum voluntary ventilation 80 litres $/ \mathrm{min}$.;

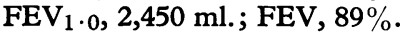

These results were now well within normal limits, with one doubtful exception: CO diffusion at rest was at the lower limit of normal (Strang, 1960).

\section{Discussion}

The history, physical findings, and results of investigation in this patient satisfy the criteria for a diagnosis of diffuse pulmonary interstitial fibrosis. The syndrome has recently been reviewed by Livingstone and his colleagues (1964) and the histological findings in this case are similar to their grades I and II. There was no history of contact with dust or mouldy hay. There were no joint or skin lesions present to suggest disseminated lupus erythematosus, rheumatoid arthritis, scleroderma, or polyarteritis nodosa. There was no evidence of a generalized xanthomatosis or of sarcoidosis: the latter was excluded by the negative Kveim test and by liver and lung biopsy. Lung biopsy also excluded the form of histiocytosis $\mathrm{X}$ that may be confined to the lungs. Repeated skin-testing and searching

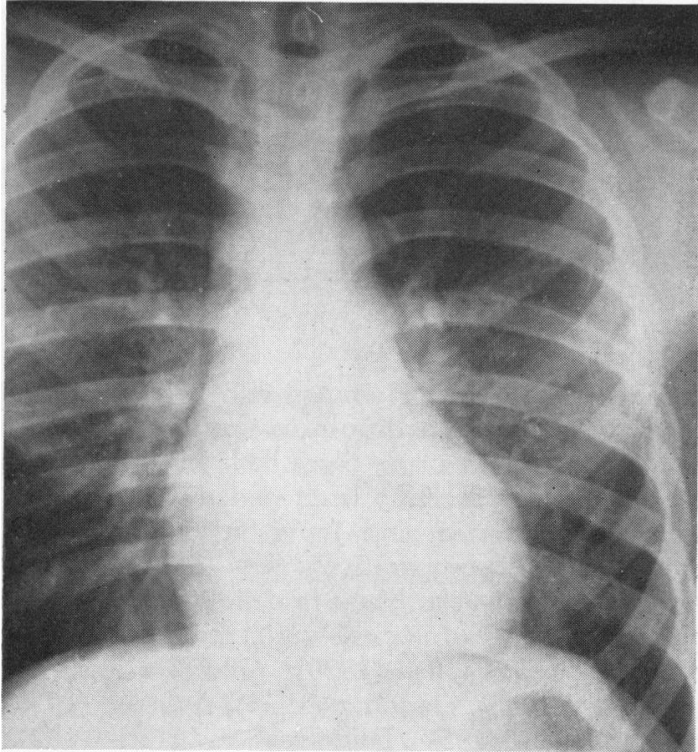

FIG. 1b.-Normal chest radiograph after steroid treatment.

for tubercle bacilli failed to show any evidence of pulmonary tuberculosis. An unusual feature was the raised alkaline phosphatase, which subsequently became normal.

In general, the prognosis in both adults and children is poor. Scadding (1960) suggests that the rapidity of progression of the disease tends to decrease with increasing age. The one natural remission in the series of Livingstone et al. (1964) was, however, in a young woman. Most of the reported childhood cases died, though a few in which the final result is not recorded failed to improve. Feinerman and Harris (1957) report details of a boy aged 8, whose diagnosis was confirmed by lung biopsy: after a year's steroid therapy he had improved clinically but not radiologically. G. S. Humphreys (1964, personal communication) described a West Indian girl aged 11, with the diagnosis confirmed by lung biopsy, who was treated with steroids and who has shown considerable clinical improvement.

The administration of steroids seems to be the only treatment of any value. Livingstone et al. (1964) gave steroids to 31 adult patients with the syndrome: of the 14 who are alive, 5 failed to respond and only one patient had both clinical and radiological remission. In their series, one patient, a 20year-old woman, recovered spontaneously without steroid therapy and has remained well for 5 years. 


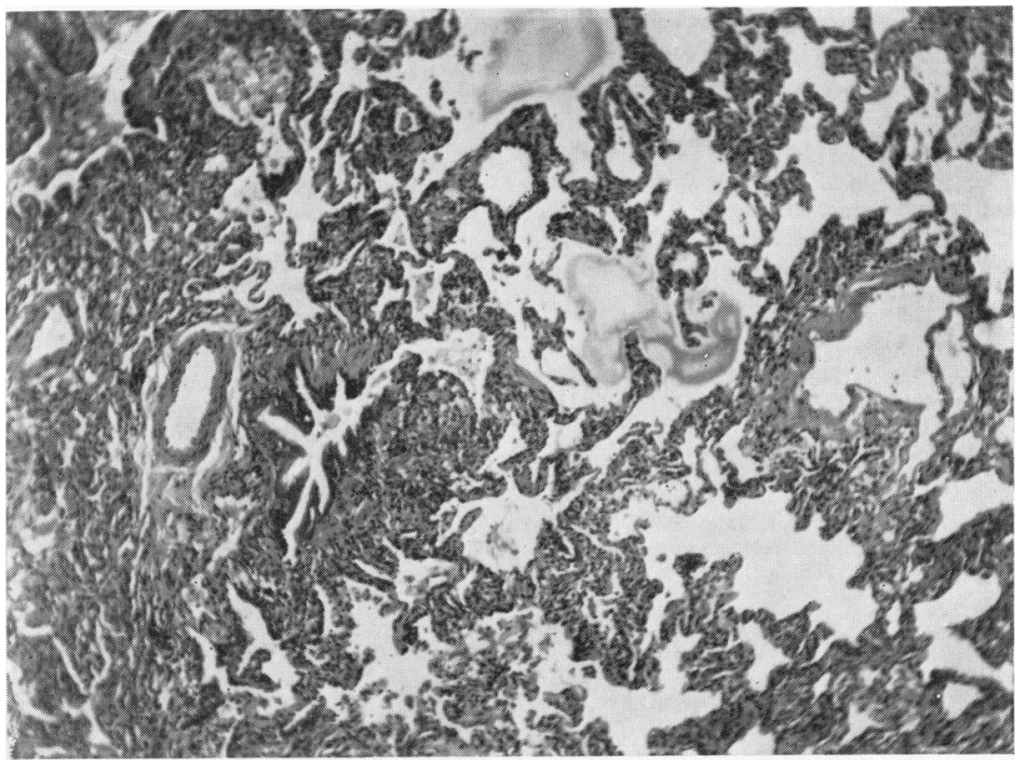

FIG. 2a.-Fibrous interstitial thickening of the alveolar walls. $(\times 83$.

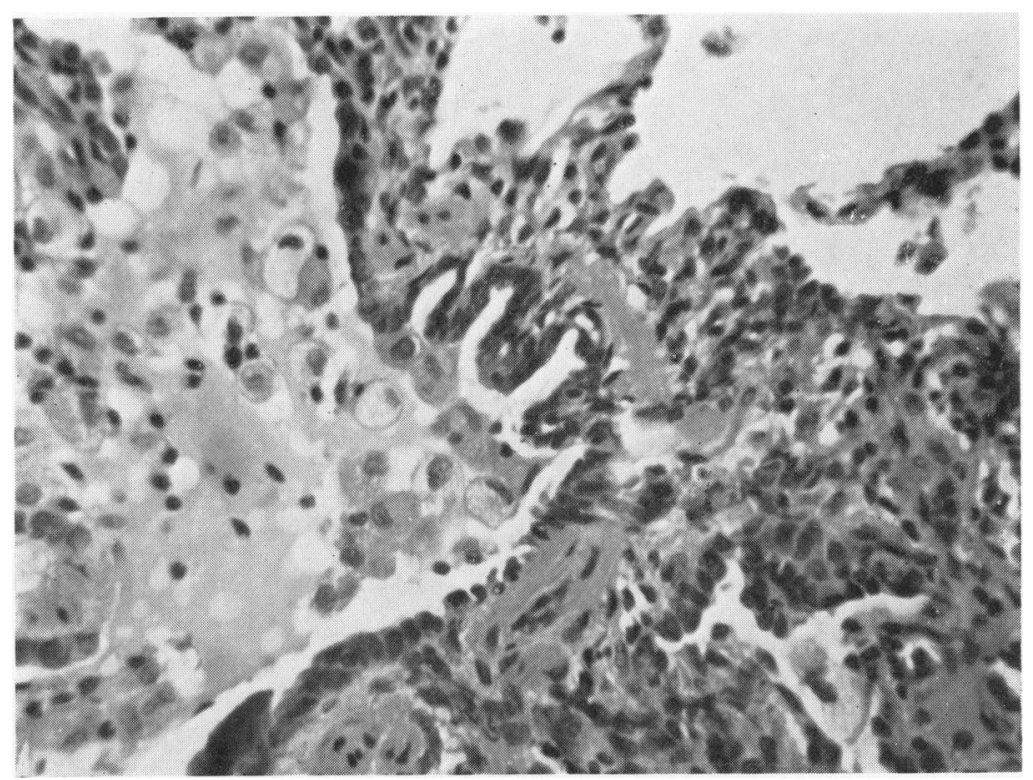

FIG. 2 b. $-(\times 330$.

These authors point out that, though lung biopsy may show a presumably irreversible fibrosis, steroids should not be withheld, as lesions elsewhere in the lungs may still be reversible. They also point out that, contrary to previous reports, steroids may be subsequently withdrawn without undue risk of relapse, provided that the withdrawal is made with caution.

\section{Summary}

A case is reported of a boy aged 13 with histologically-proven diffuse interstitial pulmonary fibrosis. 
This is the first recorded case in childhood in which improvement has been confirmed clinically, radiologically, and by pulmonary function studies.

We are indebted to Mr. R. Belsey, who performed the lung biopsy, to Dr. J. Macrae for the first series of pulmonary function studies, and to Dr. R. J. Sandry for the histology report and the photomicrograph.

\section{REFERENCES}

Aranson, A. (1956). Hamman-Rich syndrome. f. Maine med. Ass., 47, 105.

Baar, H. S., and Braid, F. (1957). Diffuse progressive interstitial fibrosis of the lungs in childhood. Arch. Dis. Childh., 32, 199.

Bradley, C. A., III (1956). Diffuse interstitial fibrosis of the lungs in children. f. Pediat., 48, 442.

Donohue, W. L. (1956). Interstitial plasma cell pneumonia. Lab. Invest., 5, 97.

, Laski, B., Uchida, I., and Munn, J. D. (1959). Familial fibrocystic pulmonary dysplasia and its relation to the HammanRich syndrome. Pediatrics, 24, 786.
Feinerman, B., and Harris, L. E. (1957). Unusual interstitial pneumonitis. Report of two cases occurring in children. Proc. Mayo Clin., 32, 637.

Grant, I. W. B., Hillis, B. R., and Davidson, J. (1956). Diffuse interstitial fibrosis of the lungs (Hamman-Rich syndrome). Amer. Rev. Tuberc., 74, 485.

Hamman, L., and Rich, A. R. (1944). Acute diffuse interstitial fibrosis of the lungs. Bull. Fohns Hopk. Hosp., 74, 177.

Hilton, H. B., and Rendle-Short, J. (1961). Diffuse progressive interestitial fibrosis of the lungs in childhood (Hamman-Rich syndrome). Arch. Dis. Childh., 36, 102.

Ivemark, B. I., and Wallgren, C. G. (1962). Diffuse interstitial pulmonary fibrosis (Hamman-Rich syndrome) in infancy. Acta paediat. (Uppsala), Suppl. 135, 97.

Livingstone, J. L., Lewis, J. G., Reid, L., and Jefferson, K. E. (1964). Diffuse interstitial pulmonary fibrosis. Quart. F. Med., 33, 71.

Mann, T. P. (1959). Diffuse progressive interstitial fibrosis of lungs in infancy. Proc. roy. Soc. Med., 52, 638.

Scadding, J. G. (1960). Chronic diffuse interstitial fibrosis of the lungs. Brit. med. F., 1, 443.

Strang, L. B. (1960). Measurements of pulmonary diffusing capacity in children. Arch. Dis. Childh., 35, 232.

Vestermark, S. (1961). Hamman-Rich syndrome. Acta paediat. (Uppsala), 50, 404 